\title{
Application of Single Nucleotide Polymorphism Markers for Selection of Male Sterility in Crop Plants
}

\author{
Shahina Akter ${ }^{1 \dagger}$, Md. Amdadul Huq ${ }^{1 \dagger}$, Yu-Jin Jung ${ }^{1}$, Yong-Gu Cho ${ }^{2}$, Kwon-Kyoo Kang ${ }^{*}$ \\ ${ }^{1}$ Department of Horticulture, Hankyong National University, Anseong 17579, Korea \\ ${ }^{2}$ Department of Crop Science, Chungbuk National University, Cheongju 28644, Korea
}

\begin{abstract}
Male sterility is an important trait and plays a key role for hybrid crop production in agricultural industry field. Different genes and enzymes are involved with male sterile traits. Dysfunction of these genes in any stage of male reproductive system often results in male sterility i.e., the inability to produce functional pollen. Functional male sterility can be utilized in the production of hybrid seed. During plant breeding for hybrid crop production, a lot of genetic diversities are created. Plant breeding is enhanced by the availability of molecular markers for rapid screening and selection in populations. Molecular markers are useful for a variety of purposes relevant to crop improvement. Functional markers that detect the functional mutations causing phenotypic changes offer a precise method for genetic identification. Various DNA markers are available now in plant breeding sectors. Among all of these markers, the new generation molecular markers called single nucleotide polymorphisms (SNPs) are most abundant, robust and feasible because of its availability in whole genome and that they play a key role in the induction of phenotypic variations like male sterility. In this review, we described the classification and mechanism of male sterility in crops, the genes responsible for male sterility, and application of SNP markers for selection of male sterile plants.
\end{abstract}

Keywords Hybrid crops, Male sterility, Molecular markers, Plant breeding, Single nucleotide polymorphisms

\section{INTRODUCTION}

Agricultural crop plants are very important for human being, therefore several strategies designed to hasten their improvement have been developed to satisfy current demands. Plant breeding program is a natural way of crop improvement and variety development. During breeding programs, a lot of genetic diversities are created, which are correlated with the phenotypes; such as male sterility (MS) quality of crops and yields, various colors and size of fruits, and tolerance to different abiotic and biotic stresses (Vidal et al. 2012; Jang et al. 2015). Genetic diversity is also created in various crop species through domestication from one geographical region to another region. The most abundant form of genomic variation is single nucleotide variation in the genome within the individuals.

MS is one of the important traits of agricultural crops. MS is the failure of plants to produce functional anthers, pollen, or male gametes. Male reproductive system in plants involves with several major developmental stages, which include production of sporogenous cells, specification of stamen primordia, tapetum and microspore mother cells (MMCs) development, meiosis, formation of free haploid microspores, degeneration of tapetum and release of mature pollen grains (Goldberg et al. 1993). Arrest of any of these steps can result in MS, the failure to produce functional pollen grains (Chase et al. 2010). Evolutionarily, MS has been a subtle means by which plants prevent self-pollination and increase genetic diversity (Hanson 1991). 
There are many factors that can create MS in plants like environmental or chemical factors. It may occur as a consequence of breeding program or through domestication of the same species in different geographical regions. MS can also result from adverse growth conditions, from diseases, or from mutations (Budar and Pelletier 2001). During breeding programs or domestication of the same species in different geographical regions or by environmental factors, a lot of genetic diversities are created in the responsible genes that lead to different phenotypes; such as MS, grain yields and quality, fruit size and color, tolerance to abiotic and biotic stresses (Vidal et al. 2012; Jang et al. 2015; Huq et al. 2016b). There are many reports on the key genes involved in male reproductive system and responsible for viable pollen development (Xing et al. 2011; Feng et al. 2013; Liu and Fan 2013; Jeong et al. 2014; Zhang and Yang 2014). Mutations in such genes often lead to abnormal pollen production and causes MS. In fact, different DNA polymorphisms are found in male sterile genes (Jeong et al. 2014). Modern sequencing technology makes it easy to find out genetic diversity among populations (Huq et al. 2016a). One of the several genetic anomalies that benefited from this advancement is the detection of single nucleotide polymorphisms (SNPs). SNP is a variation at a single position in DNA sequence among individuals of same species. SNPs are the most common DNA polymorphisms in genome sequences of human, animals, and plants. They are thought to play a major role in the induction of phenotypic variations. According to international SNP map working group, human genome sequence contains 1.42 million SNPs and average one SNP per $1.9 \mathrm{~kb}$ (Sachidanandam et al. 2001). In plants, SNP polymorphisms are found in high density across the genome (Ching et al. 2002). This review describes the classification and mechanisms of MS in plants, genes involve in MS, their genomic variation such as SNP in MS genes, and application of SNP markers for selection of male sterile lines.

\section{CLASSIFICATION OF MS}

According to Kaul (1988), MS is classified into two major groups, genetic MS and non-genetic MS. Genic male sterility (GMS) further has been classified into three subclasses on phenotypic basis such as, functional, structural and sporogenous genetic MS. Similarly, non-genetic MS is also classified into three subclasses, such as chemical, physiological and ecological MS (Kaul 1988). Furthermore, genetic MS can be classified into two groups on the basis of location of gene(s) that control the MS, such as (i) GMS (or nuclear MS) and (ii) cytoplasmic male sterility (CMS).

The MS, which is caused by nuclear genes, is called GMS. As this type of MS is controlled by the gene(s) from the nuclear compartment, it is also referred as nuclear MS. GMS has been reported in more than 175 plant species, most of which are important vegetable crop plants (Kaul 1988). GMS is the result of mutation in any genes involved in stamen development process, male gamete development process or in pollen development process. Most of the transgenic male sterile plants are created by transformation of MS related genes into the nuclear genome.

The MS which is caused by cytoplasmic genes is known as CMS. CMS is a maternally inherited trait, because mitochondrial genome is responsible for the development of such type of MS. It is also known as mitochondrial MS. CMS has been reported in as many as 150 species (Kaul 1988). CMS may result from inter-specific or inter-generic crosses, and also may be artificially induced through mutagenesis or antibiotic effects on cytoplasmic genes (Kaul 1988). Protoplast fusion is another way to develop cytoplasmic male sterile plants which has been successfully applied for several vegetables crops (Pelletier et al. 1995). In near future, it will be more easy to develop cytoplasmic male sterile plants through optimized transformation protocol into mitochondrial genome.

\section{MECHANISM OF MS}

Expression of MS (both GMS and CMS) trait in plants is associated with huge physiological, morphological, histological, biochemical and molecular changes in male reproductive tissues at various stages of growth. These changes negatively affect the synthesis of many enzymes 
which are directly and indirectly involved for pollen development and causes MS. Pollen development is a fundamental process in the plant life cycle (Wilson and Zhang 2009) which involves an exquisite pathway supported by cellular changes and the regulation of an abundant number of genes (Honys and Twell 2004; Wilson and Zhang 2009; Feng et al. 2012). Callase is an important enzyme essential for breakdown of the callose that encloses the pollen mother cells (PMCs) and helps to release the pollen from tetrad after meiosis. Pre-mature pollen is released if callase activity showed earlier. On the other hand, delayed callase activity led to delayed release of pollens, both resulting in MS (Izhar and Frankel 1971; Gottschalk and Kaul 1974). Sporopollenin is a polymer which is essential for pollen formation and it is believed that esterase isozymes play important role in the hydrolysis of sporopollenin. It is observed that male sterile plants showed reduced activity of esterase (Bhadula and Sawhney 1987; Zhou and Zhang 1994). A schematic representation of the mechanism of genetic MS is shown in Fig. 1.
GMS is an effect of mutation in the genes associated with pollen development pathway. GMS is associated with abnormal tapetum development as well as with other cytological, biochemical and molecular changes. In many cases, the growing anthers of the male sterile plants are involved with quantitative and qualitative alterations in different amino acids and enzymes. Variations are also found in the levels of specific amino acids between the anthers of fertile and sterile plants. Generally, the level of proline, phenylalanine, isoleucine, leucine, and valine is decreased, and arginine, glycine, asparagine, and aspartic acid are enhanced in the sterile anthers compared to fertile (Kaul 1988; Kumar et al. 2000). According to Kakihara et al. (1988) mature male sterile anthers contain one-eighth amount of proline compared to fertile anthers. Differences in total protein content and polypeptide bands between sterile and fertile anthers have been checked and found that sterile anthers showed lower protein content with fewer bands (Banga et al. 1984; Sawhney and Bhadula 1987).

Incompatibility between nuclear and mitochondrial

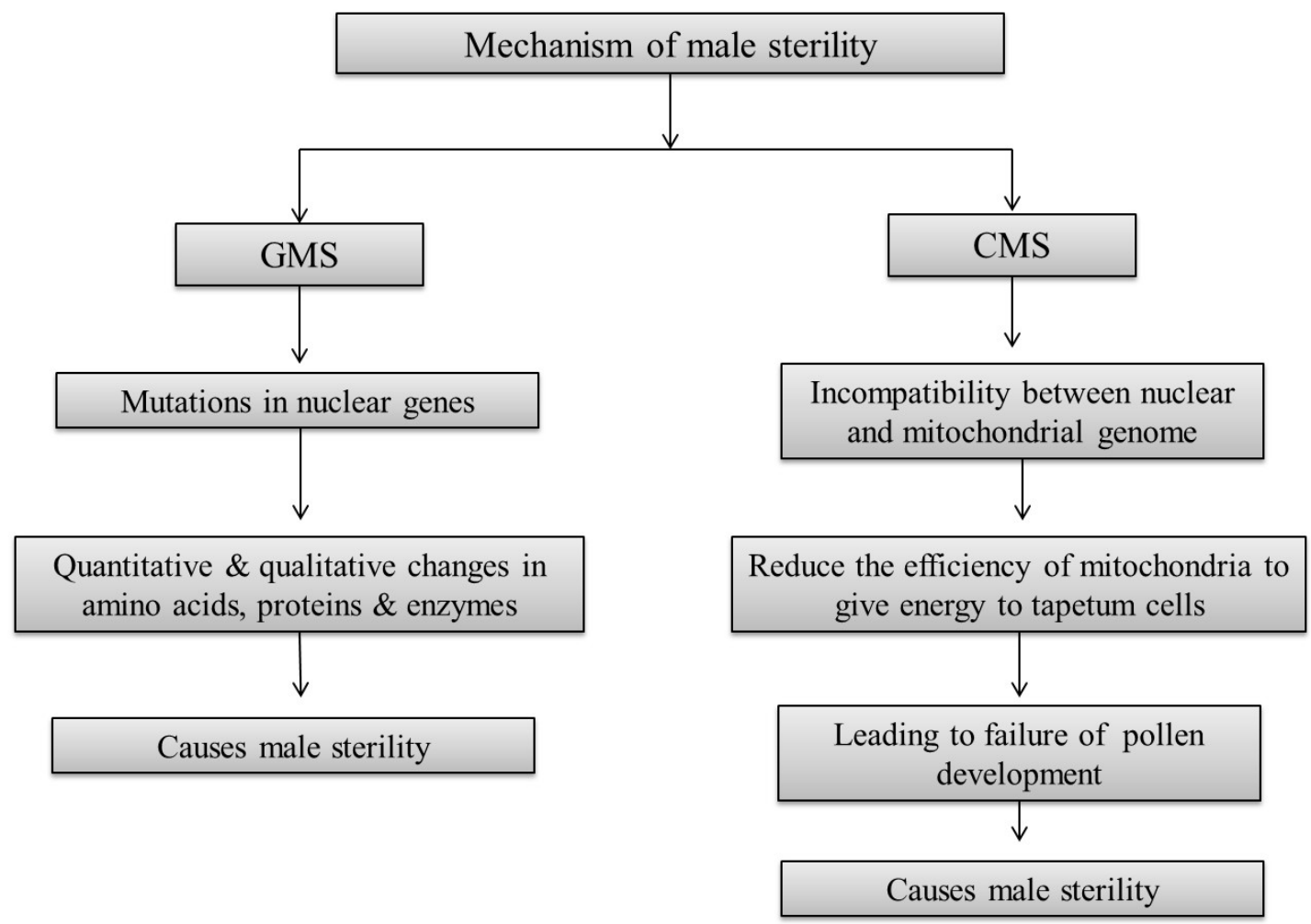

Fig. 1. Schematic representation of the mechanism of genetic male sterility. GMS: genic male sterility, CMS: cytoplasmic male sterility. 
genome causes CMS, because many mitochondrial enzymes are encoded jointly by the mitochondrial and nuclear genes. This incompatibility leads to mitochondrial dysfunction, particularly in the pollen producing organs like stamens, anther wall or tapetum. And resulting in lower efficiency of mitochondria to give energy to the tapetum cells which leads to the failure of tapetum and pollen development and consequent result is MS. Dysfunction of mitochondria is responsible for CMS because pollen producing tissues require very high energy compared to the other tissues, and dysfunctional mitochondria is unable to supply this high energy (Kumar et al. 2000).

\section{GENES RESPONSIBLE FOR MS IN IMPORTANT CROP PLANTS}

Dysfunction of any genes which are involved in the development of the male reproductive system are associated with MS, such as genes involved in sporogenous cells production pathway, tapetum and MMCs development pathway, meiosis, haploid microspores formation, degeneration of tapetum and release of mature pollen grains (Goldberg et al. 1993). Any mutations in such genes negatively affect the synthesis of amino acid and proteins. Consequently, these are translated into failed production of functional pollen and eventually causes MS (Chase et al. 2010). There are many reports about the key genes which are involved with different pathways of male reproductive system, including the differentiation of sporophytic cells (Xing et al. 2011; Feng et al. 2013), development of tapetum and microsporocyte cells (Zhang and Yang 2014), and regulation of sporopollenin synthesis and development of pollen exine (Ariizumi and Toriyama 2011; Liu and Fan 2013).

According to Jeong et al. (2014), 246 genes are involved in different steps of pollen development in tomato. Among these, one gene name $M s 10^{35}$ play the key role for pollen development and MS in tomato as it controls other genes associated with tomato male reproductive system. Further, they found that when $M s 10^{35}$ gene is mutated, pollen development is arrested at the tetrad stage. PMCs development in male sterile plant is also arrested at anaphase I during meiosis. They concluded that the reason of MS in tomato is the insertion of a retrotransposable DNA fragment (398 bp) in the promoter region near the transcription start site of $\mathrm{ms} 10^{35}$ (Jeong et al. 2014). In another study, Kaul (1988) showed more than 55 male sterile (ms) alleles causing sporogenous, structural, and functional MS. Temperature sensitive male sterile alleles in tomato such as stamenless-1 (sl-1), stamenless-2 (sl-2), $m s-15$ and $m s-33$ were also reported in several studies (Rick and Boynton 1967; Sawhney 1997).

Rice is one of the high-yielding crops and staple food for people. There are many reports about the genes which are involved in MS in rice. According to Jung et al. (2005) udt 1 is the key gene that controls the MS in rice. Many other genes were also reported which have important role in MS in rice, such as api5 (Li et al. 2011), mspl (Nonomura et al. 2003), wdal (Jung et al. 2006), and mads3 (Hu et al. 2011). Accumulating evidence showed that if any of these genes were destroyed or silenced, plants would show male-sterile phenotypes.

Maize is another important agricultural crop in the world. According to Skibbe and Schnable (2005), 52 male sterile mutants have been identified in maize and categorized as $m s 1, m s 2, m s 3, m s 4$, till $m s 52$. Any changes in these genes can lead to MS in maize.

Wheat is one of the top three staple grains in the world after rice and maize. Many studies have been conducted to find out the cause of MS in wheat and determine the responsible genes. Eleven genes have been identified from wheat which can induce GMS (Singh et al. 2015). Xi et al. (2011) identified a dominant male-sterile Ms 1376 gene from a segregated population of transgenic wheat (Xi et al. 2011). In another study, Liu et al. (2011) analyzed the mitochondrial genomes of both male sterile and fertile plants and found that 34 protein-coding genes are involved in CMS in wheat. They also identified 32 SNP in these genes of male sterile lines. A temperature sensitive male sterile gene wptms 3 from wheat was discovered by Chen et al. (2011). Some important crop plants with their responsible genes involved in MS are listed in Table 1 (Zhou et al. 2016). 
Table 1. Important crop plants with their responsible genes involved in male sterility.

\begin{tabular}{|c|c|c|}
\hline Crop species & Genes involved in male sterility & References \\
\hline \multirow[t]{3}{*}{ Tomato } & $\begin{array}{l}246 \text { genes involved in male sterility. } m s 10^{35} \text { is the key gene that regulates } \\
\text { other genes related to meiosis, tapetum development, lipid metabolism, cell } \\
\text { wall modification or degradation, and pollen wall biosynthesis. }\end{array}$ & Jeong et al. 2014 \\
\hline & More than 55 male sterility alleles have been reported. & Kaul 1988 \\
\hline & $\begin{array}{l}\text { Functional and temperature sensitive male sterility }(s l-2, m s-13, m s-15) \text { also } \\
\text { reported. }\end{array}$ & $\begin{array}{l}\text { Rick and Boynton 1967; } \\
\text { Sawhney } 1997\end{array}$ \\
\hline \multirow[t]{2}{*}{ Rice } & The key genes involved in male sterility are $u d t 1$, api5, mspl, wdal, mads 3 . & $\begin{array}{l}\text { Jung et al. 2005; Hu et al. } \\
\text { 2011; Li et al. } 2011\end{array}$ \\
\hline & A rice thermo-sensitive genic male sterile gene 5 (tms5) locus has been found. & Zhou et al. 2016 \\
\hline Maize & $\begin{array}{l}52 \text { male sterile alleles have been reported and categorized as } m s 1, \mathrm{~ms} 2, m s 3 \text {, } \\
m s 4 \text {, till } m s 52 \text {. }\end{array}$ & Skibbe and Schnable 2005 \\
\hline \multirow[t]{4}{*}{ Wheat } & Eleven genes that involved in male sterility have been identified. & Singh et al. 2015 \\
\hline & & \\
\hline & 34 protein-coding genes are involved in cytoplasmic male sterility. & Liu et al. 2011 \\
\hline & A temperature sensitive male sterile gene wptms 3 identified. & Chen et al. 2011 \\
\hline Cotton & Two genes $m s 5$ and $m s 6$ are responsible for male sterility in cotton. & Feng et al. 2015 \\
\hline
\end{tabular}

\section{APPLICATION OF SNP MARKERS FOR SELECTION OF MS}

Molecular markers can increase both the efficiency and speed of breeding programs. Various molecular markers are broadly used for analysis of genomic variations in plants, their association mapping as well as diagnostics, evolutionary studies analysis, fingerprinting, and also widely used for breeding applications. Among all molecular markers, SNPs are the most abundant and powerful, feasible for automated high-throughput genotyping, and available for multiple assay options using different technology platforms to meet the demand for genetic studies and molecular breeding in crop plants (Steemers and Gunderson 2007; Alkan et al. 2011). In present time, SNPs have gained much interest in the scientific and breeding community that could be used as potential DNA markers, which may be identified practically in every gene (Rafalski 2002). SNPs also can identify the genomic diversity of species to demonstrate the speciation and evolution, and associate genomic variations with phenotypic traits (McNally et al. 2009).

SNPs are the widely available markers for different genes. It could be also used for identification of male sterile plant and differentiates between male sterile and fertile lines. There are many reports about the successful application of SNP markers for selection of male sterile trait. Song et al. (2016) successfully developed a SNP based molecular markers for identifying male sterile gene tms 5 in two-line hybrid rice and the newly designed markers could accurately distinguish between tms 5 (male sterile) and TMS5 (wild type, male fertile) genes. According to Feng et al. (2015), two genes $m s 5$ and $m s 6$ are responsible for MS in cotton. Four SNP were identified from each gene of male sterile and male fertile lines. Using that SNP, they developed SNP markers which were successfully used to distinguish male sterile and male fertile cotton lines. Cho et al. (2006) developed SNP based molecular marker for detection of male sterile trait in onion. Liu et al. (2011) analyzed the mitochondrial DNA of both male sterile and fertile plant and found total 32 SNP in male sterile plants. From this study, they concluded that these SNP could be the reason for MS. It is also very important that by using that SNP marker it is too easy to selection of male sterile line and differentiate from male fertile lines. Ongom et al. (2016) discovered 79,728 SNPs from whole genome of male sterile sorghum. Many applicable SNP markers could be developed and could be used for the selection of sterile sorghum lines. 


\section{CONCLUSION}

As SNPs are thought to play a major role in the induction of phenotypic variation in plants, so it is very important to identify the functional SNPs regarding crop improvements. MS is very important trait for hybrid production. Identification of functional SNPs in male sterile genes of various crop plants and development of SNP markers for male sterile traits would be a great contribution for advancing plant breeding and crop improvement programs. The present sequencing technologies make it easy to find out functional SNPs from male sterile genes of different species which could be employed to efficiently distinguish male sterile and male fertile lines. Accumulating evidence indicate the crucial role of functional SNPs in controlling the MS which could be utilized to improve hybrid production.

\section{ACKNOWLEDGEMENTS}

This work was supported by a grant (National Center for GM Crops No. PJ011245: Development of GM Event Line Enhanced Multiple Disease Resistance by Antimicrobial Peptide in Rice) of the Next-Generation BioGreen 21 Program funded by the Rural Development Administration, Republic of Korea.

\section{REFERENCES}

Alkan C, Coe BP, Eichler EE. 2011. Genome structural variation discovery and genotyping. Nat. Rev. Genet. 12: 363-376.

Ariizumi T, Toriyama K. 2011. Genetic regulation of sporopollenin synthesis and pollen exine development. Annu. Rev. Plant Biol. 62: 437-460.

Banga SS, Labana KS, Banga SK. 1984. Male sterility in Indian mustard (Brassica juncea (L.) Coss.) - a biochemical characterization. Theor. Appl. Genet. 67: 515-519.

Bhadula SK, Sawhney VK. 1987. Esterase activity and isozymes during the ontogeny of stamens of male sterile lycopersicon esculentum Mill., A male sterile stamenless-2 mutant and the low temperature reverted mutant. Plant Sci. 52: 187-194.

Budar F, Pelletier G. 2001. Male sterility in plants: occurrence, determinism, significance and use. C. R. Acad. Sci. III 324: 543-550.

Chase CD, Ribarits A, Heberle-Bors E. 2010. Male sterility, p. 437-457. In: E.C. Pua, M.R. Davey (ed.). Plant developmental biology - biotechnological perspectives. Springer, Heidelberg, Germany.

Chen XD, Sun DF, Rong DF, Peng JH, Li CD. 2011. A recessive gene controlling male sterility sensitive to short daylength/low temperature in wheat (Triticum aestivum L.). J. Zhejiang Univ. Sci. B. 12: 943-950.

Ching A, Caldwell KS, Jung M, Dolan M, Smith OS, Tingey $\mathrm{S}$, et al. 2002. SNP frequency, haplotype structure and linkage disequilibrium in elite maize inbred lines. BMC Genet. 3: 19.

Cho KS, Yang TJ, Hong SY, Kwon YS, Woo JG, Park HG. 2006. Determination of cytoplasmic male sterile factors in onion plants (Allium cepa L.) using PCR-RFLP and SNP markers. Mol. Cells 21: 411-417.

Feng B, Lu D, Ma X, Peng Y, Sun Y, Ning G, et al. 2012. Regulation of the Arabidopsis anther transcriptome by DYT1 for pollen development. Plant J. 72: 612-624.

Feng X, Keim D, Wanjugi H, Coulibaly I, Fu Y, Schwarz J, et al. 2015. Development of molecular markers for genetic male sterility in Gossypium hirsutum. Mol. Breed. 35: 141.

Feng X, Zilberman D, Dickinson H. 2013. A conversation across generations: Soma-germ cell crosstalk in plants. Dev. Cell. 24: 215-225.

Goldberg RB, Beals TP, Sanders PM. 1993. Anther development: basic principles and practical applications. Plant Cell 5: 1217-1229.

Gottschalk W, Kaul MLH. 1974. The genetic control of microsporogenesis in higher plants. Nucleus 17: 133-166.

Hanson MR. 1991. Plant mitochondrial mutations and male sterility. Annu. Rev. Genet. 25: 461-486.

Honys D, Twell D. 2004. Transcriptome analysis of haploid male gametophyte development in Arabidopsis. Genome Biol. 5: R85.

Hu L, Liang W, Yin C, Cui X, Zong J, Wang X, et al. 2011. Rice MADS3 regulates ROS homeostasis during late anther development. Plant Cell 23: 515-533.

Huq MA, Akter S, Jung YJ, Nou IS, Cho YG, Kang KK. 
2016a. Genome sequencing, a milestone for genomic research and plant breeding. Plant Breed. Biotech. 4: 29-39.

Huq MA, Akter S, Nou IS, Kim HT, Jung YJ, Kang KK. 2016b. Identification of functional SNPs in genes and their effects on plant phenotypes. J. Plant Biotechnol. 43: $1-11$.

Izhar S, Frankel R. 1971. Mechanism of male sterility in Petunia: The relationship between $\mathrm{pH}$, callase activity in the anthers, and the breakdown of the microsporogenesis. Theor. Appl. Genet. 41: 104-108.

Jang SJ, Sato M, Sato K, Jitsuyama Y, Fujino K, Mori H, et al. 2015. A single-nucleotide polymorphism in an endo-1,4$\beta$-glucanase gene controls seed coat permeability in soybean. PLoS One 10: e0128527.

Jeong HJ, Kang JH, Zhao M, Kwon JK, Choi HS, Bae JH, et al. 2014. Tomato male sterile 1035 is essential for pollen development and meiosis in anthers. J. Exp. Bot. 65: 6693-6709.

Jung KH, Han MJ, Lee DY, Lee YS, Schreiber L, Franke R, et al. 2006. Wax-deficient anther1 is involved in cuticle and wax production in rice anther walls and is required for pollen development. Plant Cell 18: 3015-3032.

Jung KH, Han MJ, Lee YS, Kim YW, Hwang I, Kim MJ, et al. 2005. Rice undeveloped Tapetum1 is a major regulator of early tapetum development. Plant Cell 17: 2705-2722.

Kakihara F, Kato M, Tokumasu S. 1988. Relationship between pollen degeneration and amino acids, especially proline, in male sterile Japanese radish (Raphanus sativus L. var. longipinnatus Bailey). Sci. Hortic. 36: 17-23.

Kaul MLH. 1988. Male sterility in higher plants. Monographs on theoretical and applied genetics, 10. Springer-Verlag, Berlin.

Kumar S, Banerjee MK, Kalloo G. 2000. Male sterility: mechanisms and current status on identification, characterization and utilization in vegetables. Veg. Sci. 27: $1-24$.

Li X, Gao X, Wei Y, Deng L, Ouyang Y, Chen G, et al. 2011. Rice APOPTOSIS INHIBITOR5 coupled with two DEAD-box adenosine 5'-triphosphate-dependent RNA helicases regulates tapetum degeneration. Plant Cell 23: 1416-1434.

Liu H, Cui P, Zhan K, Lin Q, Zhuo G, Guo X, et al. 2011. Comparative analysis of mitochondrial genomes between a wheat K-type cytoplasmic male sterility (CMS) line and its maintainer line. BMC Genomics 12: 163.

Liu L, Fan XD. 2013. Tapetum: Regulation and role in sporopollenin biosynthesis in Arabidopsis. Plant Mol. Biol. 83: 165-175.

McNally KL, Childs KL, Bohnert R, Davidson RM, Zhao K, Ulat VJ, et al. 2009. Genomewide SNP variation reveals relationships among landraces and modern varieties of rice. Proc. Natl. Acad. Sci. U.S.A. 106: 12273-12278.

Nonomura K, Miyoshi K, Eiguchi M, Suzuki T, Miyao A, Hirochika H, et al. 2003. The MSP1 gene is necessary to restrict the number of cells entering into male and female sporogenesis and to initiate anther wall formation in rice. Plant Cell 15: 1728-1739.

Ongom PO, Adeyanju A, Gobena D, Rich P, Ejeta G. 2016. Sorghum MAGIC population: structure and potential for genetics research and breeding. Proc. of the: Plant and Animal Genome Conference (PAG XXIV). International Plant \& Animal Genome, San Diego, CA. P0859.

Pelletier G, Férault M, Lancelin D, Boulidard L, Dore C, Bonhomme S, et al. 1995. Engineering of cytoplasmic male sterility in vegetables by protoplast fusion. Acta Hortic. 392: 11-17.

Rafalski A. 2002. Applications of single nucleotide polymorphisms in crop genetics. Curr. Opin. Plant Biol. 5: 94-100.

Rick CM, Boynton JE. 1967. A temperature sensitive male sterile mutant of tomato. Am. J. Bot. 54: 601-611.

Sachidanandam R, Weissman D, Schmidt SC, Kakol JM, Stein LD, Marth G, et al. 2001. A map of human genome sequence variation containing 1.42 million single nucleotide polymorphisms. Nature 409: 928-933.

Sawhney VK. 1997. Genic male sterility, p. 183-198. In: K.R. Shivanna, V.K. Sawhney (ed.). Pollen biotechnology for crop production and improvement. Cambridge Univ. Press, Cambridge, England.

Sawhney VK, Bhadula SK. 1987. Characterization and temperature regulation of soluble proteins of a male sterile tomato mutant. Biochem. Genet. 25: 717-728.

Singh SP, Srivastava R, Kumar J. 2015. Male sterility systems in wheat and opportunities for hybrid wheat development. Acta Physiol. Plant. 37: 1713.

Skibbe DS, Schnable PS. 2005. Male sterility in maize. Maydica 50: 367-376.

Song FS, Ni JL, Qian YL, Li L, Ni DH, Yang JB. 2016. Development of SNP-based dCAPS markers for 
identifying male sterile gene tms5 in two-line hybrid rice. Genet. Mol. Res. 15. doi: 10.4238/gmr.15038512.

Steemers FJ, Gunderson KL. 2007. Whole genome genotyping technologies on the BeadArray platform. Biotechnol. J. 2: 41-49.

Vidal RO, do Nascimento LC, Mondego JM, Pereira GA, Carazzolle MF. 2012. Identification of SNPs in RNA-seq data of two cultivars of Glycine max (soybean) differing in drought resistance. Genet. Mol. Biol. 35 (1 suppl): 331-334.

Wilson ZA, Zhang DB. 2009. From Arabidopsis to rice: pathways in pollen development. J. Exp. Bot. 60: 1479-1492.

Xi YJ, Ma XF, Zhong H, Liu SD, Wang ZL, Song YY, et al. 2011. Characterization of a male sterile mutant from progeny of a transgenic plant containing a leaf senescence-inhibition gene in wheat. Euphytica 177: 241-251.

Xing S, Salinas M, Huijser P. 2011. New players unveiled in early anther development. Plant Signal. Behav. 6: 934-938.

Zhang D, Yang L. 2014. Specification of tapetum and microsporocyte cells within the anther. Curr. Opin. Plant Biol. 17: 49-55.

Zhou C, Zhang Y. 1994. Studies on several properties of radish male-sterility. Acta Hortic. Sin. 21: 65-70.

Zhou H, Li J, Zhu L, Jiang D, Dong J, Liu Q. 2016. RNase ZS1 mediates UbL40 mRNAs decay controlling thermo-sensitive genic male sterility in rice. Proc. of the: Plant and Animal Genome Conference (PAG XXIV). International Plant \& Animal Genome, San Diego, CA. P0737. 